\title{
Originals
}

\section{Angiotensin converting enzyme inhibition prevents development of muscle and nerve dysfunction and stimulates angiogenesis in streptozotocin-diabetic rats}

\author{
N.E. Cameron, M. A. Cotter and S. Robertson \\ School of Biomedical Sciences, University of Aberdeen, Scotland, UK
}

\begin{abstract}
Summary. The effects of the angiotensin converting enzyme inhibitor lisinopril on slow and fast twitch muscle contractile properties, nerve conduction and hypoxic resistance, and muscle and nerve capillary density were examined in streptozotocin-diabetic rats. Prolongation of soleus contraction and relaxation were partially prevented by treatment $(p<0.01)$. A $22 \%$ deficit in fast twitch extensor digitorum longus tetanic tension production was also ameliorated $(p<0.01)$. Sciatic motor and sensory conduction velocity, $25 \%$ and $12 \%$ reduced by diabetes respectively, were $75 \%$ normalized by lisinopril $(p<0.01)$. There was a $47 \%$ increase in resistance to hypoxic conduction block with diabetes $(p<0.01)$. Lisinopril treatment resulted in normal hypoxic resistance. Capillarisation of nerve and muscle was little affected by diabetes; however, there was a $17 \%$ increase in capillary density in sci-
\end{abstract}

atic nerve, and a $40 \%$ increase in extensor digitorum longus muscle with lisinopril $(p<0.01)$. For soleus, a smaller treatment-induced increase in capillary density led to an elevated capillary/muscle fibre ratio $(p<0.01)$. These results suggest that lisinopril promoted angiogenesis. It was concluded that the beneficial effect of preventive lisinopril treatment is likely to depend upon a reduction of peripheral vascular resistance and improvement of tissue blood flow, which implicates relative hypoxia as an important factor in the development of myopathy and neuropathy in experimental diabetes.

Key words: Neuropathy, hypoxia, ischaemia, nerve conduction, muscle contraction, capillary density, lisinopril, , angiotensin converting enzyme.
Reduced nerve conduction velocity and increased resistance to ischaemic conduction block are features of nerve dysfunction commonly found in diabetic patients and animal models [1]. The mechanisms underlying the aetiology of diabetic neuropathy remain controversial. Largely based on animal experiments, one school of thought considers that metabolic alterations are primarily responsible. Thus, a hyperglycaemia-induced enhancement of polyol pathway flux has been suggested to reduce nerve myo-inositol levels and phosphoinositide turnover, compromising $\mathrm{Na}-\mathrm{K}$ adenosine triphosphatase (ATPase) activity. The resultant changes in ionic homeostasis may be responsible for a number of functional and morphological deficits including eventual axonopathy [2]. Aldose reductase inhibitors correct nerve dysfunction in diabetic rats [3-6], and may also have some beneficial effects on nerve fibre growth and repair in diabetic patients [7].

Low and co-workers have demonstrated reduced nerve blood flow and endoneurial hypoxia in rat sciatic nerve which is sufficiently severe so as to contribute to dysfunction [1]. Aspects of endothelial control of vascular resistance may be important as there is reduced basal prostacyclin synthesis from diabetic rat sciatic nerves [8]. Endoneurial hypoxia has also been observed in neuropathic diabetic patients [9]. Chronic electrical stimulation, and guanethidine treatment to reduce sympathetic vasomotor tone, improve nerve blood flow and conduction velocity $[10,11]$. Thus, despite reports of increased blood flow in the first few months of diabetes in rats [12], it is plausible that vascular factors are important in the aetiology of diabetic neuropathy.

Striated muscle is also affected by diabetes [13]. Like nerve, this has been linked to polyol pathway activity as the effects are ameliorated by aldose reductase inhibitors and are also found in both cardiac and skeletal muscle of galactosaemic rats [14-16]. Unlike nerve, however, there is no evidence for the involvement of abnormal myo-inositol metabolism [15]. In heart and skeletal muscle there are also indications of vascular dysfunction with diabetes [17-19]. Thus, it is possible that reduced perfusion may also contribute to diabetic myopathy.

Angiotensin II is a powerful circulating vasoconstrictor, which may contribute to vascular tone in nerve and muscle circulatory beds. Reactivity to angiotensin may be 


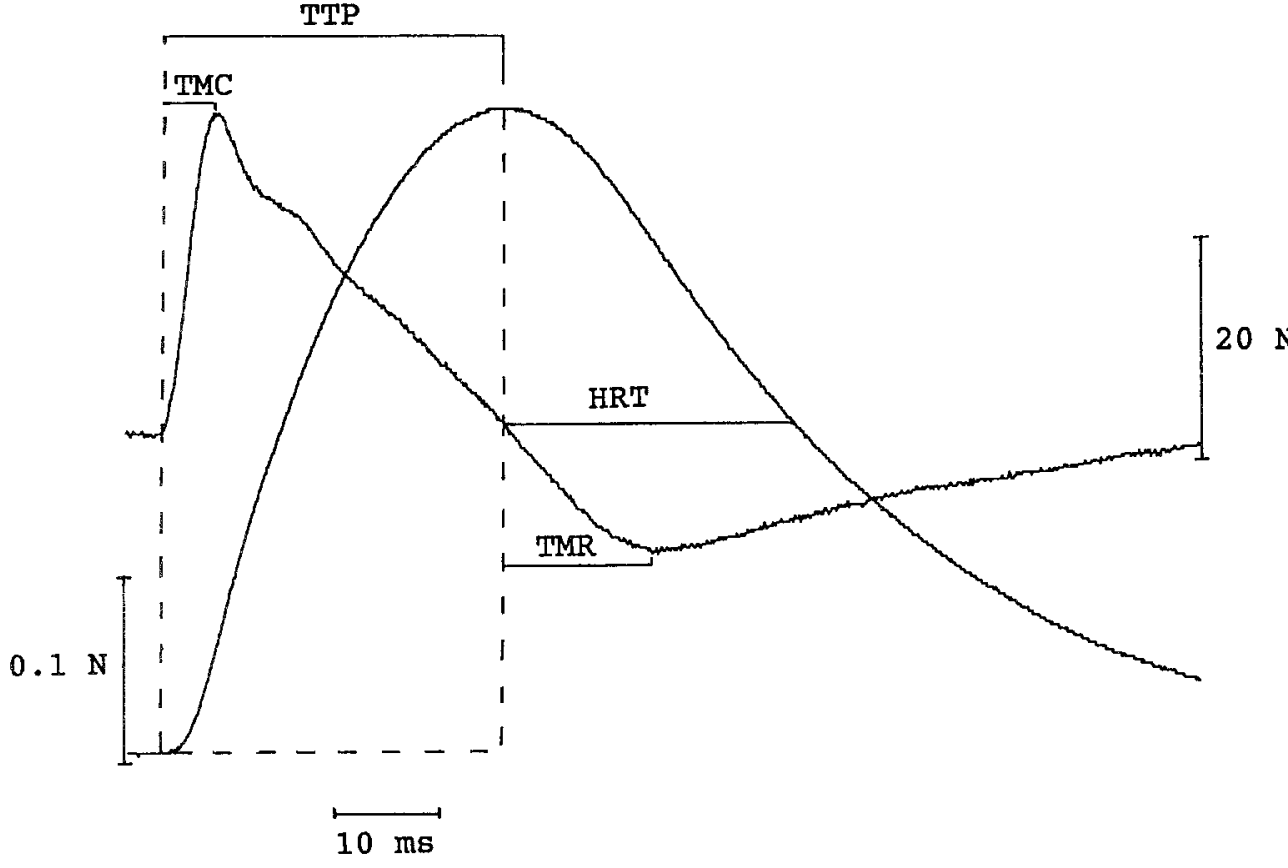

Fig. 1. A typical recording of a soleus muscle twitch, and its differentiated derivative used to measure rates of change. For the tension trace, developed tension in Newtons $(\mathrm{N})$, time to peak tension (TTP), and half relaxation time (HRT) in ms were measured. For the derivative, time to reach the maximum contraction (TMC) and relaxation (TMR) rates in $\mathrm{ms}$ as well as maximum rates in $\mathrm{N} / \mathrm{s}$ were measured increased in vessels in the absence of insulin [20]. The aim of the present investigation was to ascertain whether angiotensin converting enzyme (ACE) inhibition could prevent the development of neuropathy and myopathy in diabetic rats.

Chronic blood flow increases in striated muscles of non-diabetic animals result in angiogenesis [21]. A secondary aim of the investigation was to ascertain in diabetic rats whether capillarisation of nerve and skeletal muscles was affected by treatment.

\section{Materials and methods}

Mature male 19-week-old Sprague-Dawley rats (Aberdeen University colony) were used. Non-diabetic animals acted as onset controls, others were given streptozotocin $(45 \mathrm{mg} / \mathrm{kg}$ in $20 \mathrm{mmol} / \mathrm{l}$ sodium citrate buffer, $\mathrm{pH} 4.5$, i.p.). Diabetes was verified $24 \mathrm{~h}$ later by estimating hyperglycaemia and glycosuria (Visidex II and Diastix; Ames, Slough, UK). Samples for plasma glucose measurement were taken the day of final experiments.

Diabetic animals were divided into two groups, one of which was untreated for two months, the other was given lisinopril (Zestril, I.C.I., Macclesfield, Cheshire, UK) [22] dissolved in the drinking water at a concentration which resulted in rats receiving approximately $20 \mathrm{mg} \cdot \mathrm{kg}^{-1} \cdot \mathrm{day}^{-1}$.

In final experiments ( $1-1.5 \mathrm{~g} / \mathrm{kg}$ urethane anaesthesia i.p.), conduction velocity was measured in vivo between the sciatic notch and the knee for motor branches supplying the tibialis anterior (peroneal division) and gastrocnemius (tibial division) muscles. Sensory conduction velocity was measured in the saphenous nerve between the groin and ankle. Rectal and nerve temperatures were monitored, and regulated between 36.5 and $37.5^{\circ} \mathrm{C}$. The methods have previously been described in detail $[4,5]$.

Contractile properties for slow twitch soleus and fast twitch extensor digitorum longus (EDL) muscles were measured in vivo as previously described $[13,15]$. Muscles were freed from connecting tissue and distal tendons were tied and attached to an isometric tension transducer. The femur was fixed rigidly with a metal clamp and the foot was pinned to a cork board. Muscles were stimulated via their motor nerves $(0.3 \mathrm{~ms}$ pulse width, $2-10 \mathrm{~mA})$. Throughout recordings muscle surface temperature was monitored by a thermocouple probe and kept at $37^{\circ} \mathrm{C}$ by irrigation with $0.9 \% \mathrm{NaCl}$ at $40^{\circ} \mathrm{C}$. Muscle length was adjusted for maximal twitch tension. An average of eight separate twitches was used to determine contractile properties. A typical twitch is shown in Figure 1 to illustrate the measurements. These included, time to peak tension (TTP) and half relaxation time (HRT). Tension traces were differentiated and further measurements were made for the times taken to reach maximum contraction (TMC) and relaxation (TMR) rates. Similar measurements were made for tetany; muscles being stimulated for $750 \mathrm{~ms}$ at $350 \mathrm{~Hz}$ (EDL) or $250 \mathrm{~Hz}$ (soleus), optimal frequencies for tension production [15]. Maximum tetanic rates were divided by tension to obtain specific contraction (SCR) and relaxation (SRR) rates. Muscle cross-sectional area was estimated from weight and length. Length was measured before distal tendons were cut. For soleus the leg was held in full flexion, and for EDL in full extension.

Sciatic nerve hypoxic resistance was measured in vitro as previously described [23]. The contralateral sciatic trunk was removed and mounted on bipolar stimulating (proximal end) and recording (distal end) electrodes in a chamber containing Krebs-Ringer solution at $35^{\circ} \mathrm{C}$, with $5.5 \mathrm{mmol} / 1$ glucose for nerves from non-diabetic, and $40 \mathrm{mmol} / \mathrm{l}$ glucose for the diabetic rats. Bathing fluid was gassed with $95 \% \mathrm{O}_{2}, 5 \% \mathrm{CO}_{2}$. Nerves were equilibrated for $30 \mathrm{~min}$, then the chamber was re-filled with mineral oil pre-gassed for $1 \mathrm{~h}$ with $100 \%$ $\mathrm{N}_{2}$. Nerves were stimulated with just supramaximal pulses $(1 \mathrm{~Hz}$, $0.05 \mathrm{~ms}$ width, $10 \mathrm{~mA}$ ) and compound action potential amplitude was monitored at 2 -min intervals until it fell below $10 \%$ of its initial value.

At the end of the experiment, rats were killed by exsanguination. Just before this, approximately $2.5 \mathrm{~cm}$ of the sciatic nerve trunk, between the sciatic notch and its bifurcation at the knee, was removed and divided into five pieces which were mounted together, along with soleus, EDL and tibialis anterior muscle which also acted as support tissue [23]. Samples were frozen in isopentane pre-chilled in liquid nitrogen, $10 \mu \mathrm{m}$ sections were cut on a cryostat, and capillary endothelium was stained for alkaline phosphatase using the method of Ziada et al. [24]. Three sections, each $90 \mu \mathrm{m}$ apart, were taken and all capillaries in all nerve fascicles were counted with the aid of a projection microscope. Fascicle outlines were traced and their areas measured using a digitizing pad linked to a microcomputer. Thus, the measurements represent average capillary density for repeated sampling between sciatic notch and knee, on a combined fascicular area of approximately $10 \mathrm{~mm}^{2}$ for each nerve. There were no signifi- 
Table 1. Body and muscle weights, and muscle tension production

\begin{tabular}{|c|c|c|c|c|c|c|c|}
\hline \multirow[t]{2}{*}{ Group } & \multirow{2}{*}{$\begin{array}{l}\text { Body } \\
\text { weight } \\
\text { (g) }\end{array}$} & \multicolumn{3}{|l|}{ Soleus } & \multicolumn{3}{|c|}{ Extensor digitorum longus } \\
\hline & & $\begin{array}{l}\text { Muscle } \\
\text { weight } \\
\text { (g) }\end{array}$ & $\begin{array}{l}\text { Twitch } \\
\text { tension } \\
\left(\mathrm{mN} / \mathrm{mm}^{2}\right)\end{array}$ & $\begin{array}{l}\text { Tetanic } \\
\text { tension } \\
\left(\mathrm{mN} / \mathrm{mm}^{2}\right)\end{array}$ & $\begin{array}{l}\text { Muscle } \\
\text { weight } \\
\text { (g) }\end{array}$ & $\begin{array}{l}\text { Twitch } \\
\text { tension } \\
\left(\mathrm{mN} / \mathrm{mm}^{2}\right)\end{array}$ & $\begin{array}{l}\text { Tetanic } \\
\text { tension } \\
\left(\mathrm{mN} / \mathrm{mm}^{2}\right)\end{array}$ \\
\hline $\begin{array}{l}\text { Diabetic } \\
(n=13)\end{array}$ & $\begin{array}{r}423 \\
\pm 21\end{array}$ & $\begin{array}{r}0.238 \\
\pm 0.009\end{array}$ & $\begin{array}{r}58.1 \\
\pm 4.1\end{array}$ & $\begin{array}{c}303^{b} \\
\pm 17\end{array}$ & $\begin{array}{r}0.169^{\mathrm{a}} \\
\pm 0.014\end{array}$ & $\begin{array}{r}80.3 \\
\pm 6.2\end{array}$ & $\begin{array}{c}409^{\mathrm{b}} \\
\pm 22\end{array}$ \\
\hline
\end{tabular}

Values are mean \pm SEM. N, Newton

${ }^{\mathrm{a}} p<0.05,{ }^{\mathrm{b}} p<0.01$, difference vs control group; ${ }^{\mathrm{c}} p<0.01$, lisinopril vs diabetic group

Table 2. Soleus muscle speed-related contractile properties

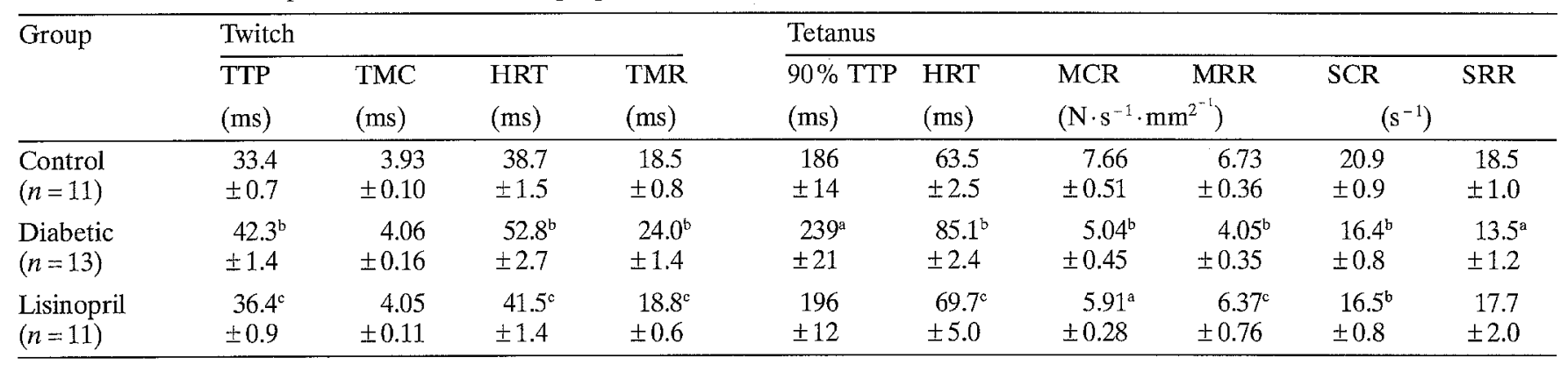

TTP, time to peak twitch tension; TMC, time to maximum contraction rate; HRT, half relaxation time; TMR, time to maximum relaxation rate; $90 \%$ TTP, time to reach $90 \%$ of maximum tetanic tension; MCR, maximum contraction rate; MRR, maximum relaxation rate;

cant differences between average fascicular areas between groups. For soleus and EDL muscles, measurements were made on three $1 \mathrm{~mm}^{2}$ areas selected at random. This represents sampling of approximately half of the muscle cross-sectional area. All capillaries and muscle fibres within these areas were counted, and the results expressed as capillary density and capillary/fibre ratio.

\section{Sciatic nerve polyol levels}

Just before exsanguination, part of the sciatic nerve proximal and distal to the sample for capillary measurements, was taken for nerve sugar and polyol measurement and frozen in liquid $\mathrm{N}_{2}$. Trimethylsilyl derivatives were prepared from aqueous deproteinized extracts and analysed by gas chromatography $[4,25]$.

\section{Statistical analysis}

Data are expressed as mean \pm SEM. One-way analysis of variance was performed, followed by Duncan's multiple range test $[26,27]$ to assign differences to individual groups where overall significance $(p<0.05)$ was attained.

\section{Results}

Diabetic animals exhibited hyperphagia and polydipsia, and there was no indication that this was affected by treatment. Plasma glucose levels were $40.6 \pm 2.4 \mathrm{mmol} / \mathrm{l}$ for untreated and $35.9 \pm 2.2 \mathrm{mmol} / \mathrm{l}$ for treated rats. Body
SCR, specific contraction rate; SRR, specific relaxation rate, $\mathrm{N}=$ Newton. Values are mean $\pm \mathrm{SEM}$.

${ }^{\mathrm{a}} p<0.05$, ${ }^{\mathrm{b}} p<0.01$, difference vs control group; ${ }^{\circ} p<0.01$, lisinopril vs diabetic group

weight was similarly reduced compared to onset control animals in both groups (Table 1).

Muscle weight for soleus was unaffected by diabetes, whereas for EDL it was reduced by $17 \%$. Tension production by soleus during a twitch tended to be slightly reduced by diabetes, significantly so for the lisinopril-treated group $(p<0.05)$. Tetanic tension was $17 \%$ reduced by diabetes but this was prevented by treatment. EDL twitch tension was not significantly affected, but there was a $22 \%$ deficit in tetanic tension production which was prevented by treatment.

Table 2 lists soleus speed-related contractile properties. Twitch contraction times were prolonged by diabetes; TTP was $27 \%$ increased although TMC was relatively unaffected. TTP was within the control range with treatment. Relaxation was also markedly affected with $36 \%$ and $30 \%$ prolongations of HRT and TMR respectively. Twitch relaxation was not significantly different from nor$\mathrm{mal}$ in the lisinopril-treated group. Tetanic $90 \%$ TTP was $28 \%$ prolonged by diabetes, and this was reduced to $5 \%$ by treatment although values were not significantly different from either non-diabetic or diabetic control animals. HRT increased by $34 \%$ with diabetes, and this was reduced to $10 \%$ by lisinopril. Maximum rates of contraction were decreased by diabetes and this was unaffected by treatment whether expressed as a raw rate corrected for muscle cross-sectional area, or corrected for differences in tension production. Maximum relaxation rates were reduced by $40 \%$ and this was largely $(87 \%)$ prevented by 
Table 3. Extensor digitorum longus speed-related contractile properties

\begin{tabular}{|c|c|c|c|c|c|c|c|c|}
\hline \multirow{3}{*}{$\begin{array}{l}\text { Group } \\
\text { Control } \\
(n=11)\end{array}$} & \multicolumn{4}{|c|}{ Twitch } & \multicolumn{4}{|c|}{ Tetanus } \\
\hline & \multirow{2}{*}{$\begin{array}{r}\text { ТТР } \\
12.1 \\
\pm 0.3\end{array}$} & \multicolumn{2}{|c|}{$\begin{array}{c}\text { TMC HRT } \\
(\mathrm{ms}) \\
\end{array}$} & TMR & \multicolumn{2}{|c|}{$\begin{array}{l}\text { MCR MRR } \\
\left(\mathrm{N} \cdot \mathrm{s}^{-1} \cdot \mathrm{mm}^{2^{-1}}\right)\end{array}$} & \multicolumn{2}{|c|}{$\begin{array}{c}\text { SCR SRR } \\
\left(\mathrm{s}^{-1}\right) \\
\end{array}$} \\
\hline & & $\begin{array}{r}3.50 \\
\pm 0.09\end{array}$ & $\begin{array}{r}12.2 \\
\pm 0.6\end{array}$ & $\begin{array}{r}5.84 \\
\pm 0.52\end{array}$ & $\begin{array}{r}17.4 \\
\pm 1.0\end{array}$ & $\begin{array}{r}22.1 \\
\pm 1.4\end{array}$ & $\begin{array}{r}34.8 \\
\pm 1.4\end{array}$ & $\begin{array}{r}42.3 \\
\pm 2.4\end{array}$ \\
\hline $\begin{array}{l}\text { iabetic } \\
=13)\end{array}$ & $\begin{array}{r}13.1 \\
\pm 0.4\end{array}$ & $\begin{array}{r}3.60 \\
\pm 0.10\end{array}$ & $\begin{array}{r}11.2 \\
\pm 0.7\end{array}$ & $\begin{array}{r}6.20 \\
\pm 0.46\end{array}$ & $\begin{array}{r}16.4 \\
\pm 0.9\end{array}$ & $\begin{aligned} & 14.8^{\mathrm{a}} \\
\pm & 1.6\end{aligned}$ & $\begin{array}{r}40.6 \\
\pm 1.8\end{array}$ & $\begin{array}{r}35.5 \\
\pm 2.9\end{array}$ \\
\hline $\begin{array}{l}\text { Lisinopril } \\
(n=11)\end{array}$ & $\begin{array}{r}12.7 \\
\pm 0.2\end{array}$ & $\begin{array}{r}3.43 \\
\pm 0.06\end{array}$ & $\begin{array}{r}12.0 \\
\pm 0.4\end{array}$ & $\begin{array}{r}6.15 \\
\pm 0.51\end{array}$ & $\begin{array}{r}20.0^{\mathrm{b}} \\
\pm 1.2\end{array}$ & $\begin{array}{l}22.8^{\circ} \\
\pm 2.7\end{array}$ & $\begin{array}{r}40.2 \\
\pm 2.6\end{array}$ & $\begin{array}{r}44.3^{b} \\
\pm 3.3\end{array}$ \\
\hline
\end{tabular}

TTP, time to peak twitch tension; TMC, time to maximum contraction rate; HRT, half relaxation time; TMR, time to maximum relaxation rate; $\mathrm{MCR}$, maximum contraction rate; $\mathrm{MRR}$, maximum relaxation rate; $S C R$, specific contraction rate; $S R R$, specific relaxation rate $\mathrm{N}, \mathrm{Newton}$. Values are mean $\pm \mathrm{SEM}$.

${ }^{a} p<0.05$, difference vs control group; ${ }^{\mathrm{b}} p<0.05,{ }^{\mathrm{c}} p<0.01$, lisinopril vs diabetic group

Table 4. Nerve conduction and resistance to hypoxia

\begin{tabular}{lcccccc}
\hline Group & $\begin{array}{l}\text { Gastro- } \\
\text { cnemius } \\
(\mathrm{m} / \mathrm{s})\end{array}$ & $\begin{array}{l}\text { Tibialis } \\
\text { anterior } \\
(\mathrm{m} / \mathrm{s})\end{array}$ & $\begin{array}{l}\text { Average } \\
\text { motor } \\
(\mathrm{m} / \mathrm{s})\end{array}$ & $\begin{array}{l}\text { Saphe- } \\
\text { nous } \\
(\mathrm{m} / \mathrm{s})\end{array}$ & $\begin{array}{l}\mathrm{T}_{50} \\
(\mathrm{~min})\end{array}$ & $\mathrm{T}_{80}$ \\
$(\mathrm{~min})$ \\
\hline Control & 65.4 & 62.6 & 64.1 & 59.3 & 17.7 & 21.4 \\
$(n=11)$ & \pm 2.1 & \pm 2.2 & \pm 1.8 & \pm 1.3 & \pm 0.5 & \pm 0.6 \\
Diabetic & $50.8^{\mathrm{a}}$ & $48.2^{\mathrm{a}}$ & $49.5^{\mathrm{a}}$ & $50.7^{\mathrm{a}}$ & $24.7^{\mathrm{a}}$ & $32.1^{\mathrm{a}}$ \\
$(n=13)$ & \pm 1.6 & \pm 1.4 & \pm 1.1 & \pm 1.2 & \pm 0.9 & \pm 0.9 \\
Lisinopril & $59.8^{\mathrm{b}}$ & $63.2^{\mathrm{b}}$ & $61.5^{\mathrm{b}}$ & $57.3^{\mathrm{b}}$ & $16.9^{\mathrm{b}}$ & $23.8^{\mathrm{b}}$ \\
$(n=11)$ & \pm 1.7 & \pm 1.6 & \pm 0.9 & \pm 1.2 & \pm 1.3 & \pm 1.2 \\
\hline
\end{tabular}

$\mathrm{T}_{50}$, time for compound action potential amplitude to be reduced by $50 \% ; \mathrm{T}_{80}$, time for compound action potential amplitude to be reduced by $80 \%$. Values are mean \pm SEM.

${ }^{a} p<0.01$, difference vs control group; ${ }^{\circ} p<0.01$, lisinopril vs diabetic group

lisinopril. Part of the effect may have been due to reduced tension production by the diabetic group, as the difference fell to $27 \%$ for specific relaxation rate.

Speed-related contractile properties for EDL are given in Table 3. There was no significant effect of diabetes on twitch contraction and relaxation. Maximum contraction rates may have been slightly reduced by diabetes, particularly when compared to lisinopriltreated animals; however, this difference disappeared when corrected for differences in tension production. There was a $33 \%$ decrease in maximum relaxation rate, which was prevented by treatment. As with soleus, part of this may be accounted for by reduced tension production, although a significant difference $(p<0.05)$ remained between diabetic control and lisinopril-treated groups for specific relaxation rate.

Nerve conduction velocity values are given in Table 4. There was an average $25 \%$ reduction in motor nerve conduction velocity with diabetes compared to onset controls. This was $77 \%$ prevented by lisinopril, the resulting values were not significantly different from those of controls. Sensory saphenous nerve conduction velocity was $12 \%$ reduced by diabetes, and this was $73 \%$ prevented by treatment. In a previous study we found no statistically signifi- cant increase in nerve conduction velocity in normal controls over the time period investigated [5]. Absolute starting values and relative changes in compound action potential amplitude (CAPA) with hypoxia are plotted in Figure 2. After an initial period of hyperexcitability [28], CAPA declined more slowly in diabetic animals than onset controls. The curve for the lisinopril-treated group did not show hyperexcitability, but during the later decline it followed that of non-diabetic controls quite closely. This is reflected in $\mathrm{T}_{50}$ and $\mathrm{T}_{80}$ values (Table 4 ) which were $47 \%$ and $50 \%$ prolonged by diabetes but were not significantly different to onset controls with lisinopril treatment.

Sciatic nerve sugar and polyol levels are shown in Table 5. Sorbitol and fructose were 9.2-fold and 9.5-fold elevated respectively in diabetic nerves, and were unaffected by treatment. Myo-inositol was $23 \%$ decreased in the diabetic group, and this was $14 \%$ further reduced by lisinopril treatment.

Details of sciatic nerve and soleus and EDL muscle capillarisation are given in Table 6. For sciatic nerve, capillary density was unaffected by diabetes, but was $17 \%$ increased with lisinopril. Figure 3 shows a positive correlation between average sciatic nerve motor conduction velocity and capillary density for treated and untreated diabetic rats. For soleus muscle there was a $10 \%$ increase in capillary density with lisinopril and a $4 \%$ increase with diabetes alone. Despite no significant changes in muscle

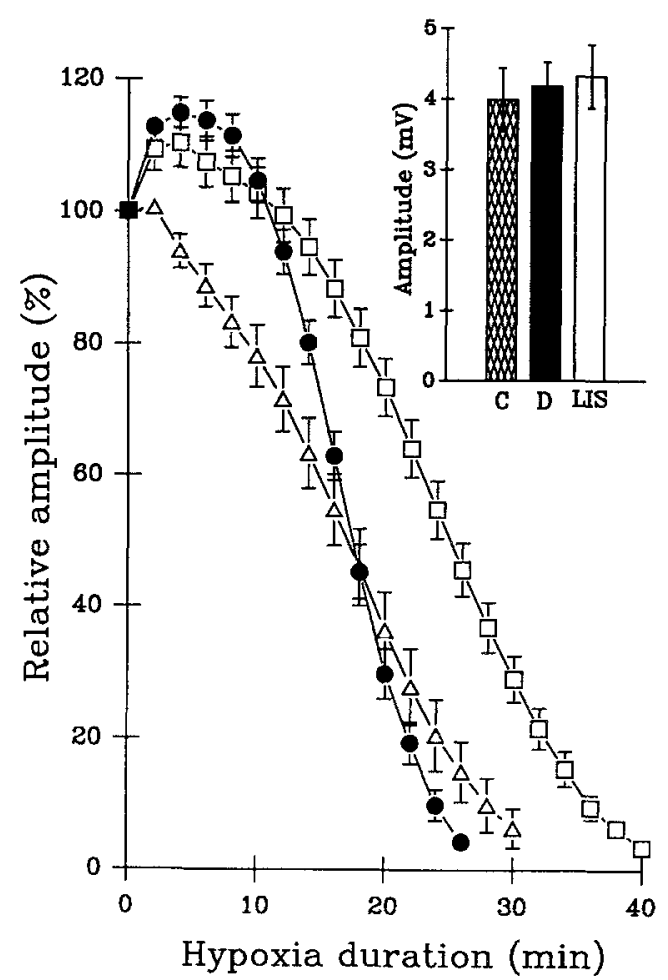

Fig. 2. Percentage change in sciatic nerve compound action potential amplitude with duration of hypoxia. Symbols and error bars show group mean \pm SEM; non-diabetic control ( $)$, diabetic control $(\square)$, and lisinopril-treated diabetic $(\triangle)$ groups. The inset histogram shows initial sciatic nerve compound action potential amplitudes before the period of hypoxia for non-diabetic control ( $C$, diabetic control (D, $\mathbf{v})$ and lisinopril-treated diabetic (LIS, $\square$ ) groups. There were no significant differences between groups in initial amplitude 
Table 5. Sciatic nerve polyol levels

\begin{tabular}{lccc}
\hline Group & \multicolumn{1}{l}{ Sorbitol } & Fructose & Myo-inositol \\
\cline { 2 - 4 } & \multicolumn{2}{c}{ (nmol/mg wet weight) } & \\
\hline Control & 0.28 & 0.90 & 2.86 \\
& \pm 0.02 & \pm 0.07 & \pm 0.22 \\
Diabetic & $2.59^{\mathrm{b}}$ & $8.57^{\mathrm{b}}$ & $2.19^{\mathrm{a}}$ \\
& \pm 0.12 & \pm 0.31 & \pm 0.09 \\
Lisinopril & $2.49^{\mathrm{b}}$ & $7.56^{\mathrm{b}}$ & $1.78^{\mathrm{b}, \mathrm{c}}$ \\
& \pm 0.07 & \pm 0.38 & \pm 0.07 \\
\hline
\end{tabular}

Values are mean \pm SEM.

${ }^{a} p<0.05,{ }^{b} p<0.01$ difference vs control group; ${ }^{c} p<0.01$, lisinopril vs diabetic group

fibre density, the capillary/fibre ratio was marginally increased by diabetes $(p<0.05)$, and this was more apparent $(12 \%)$ with lisinopril $(p<0.01)$. For EDL, there was a $15 \%$ increase in capillary density with diabetes, rising to $40 \%$ with treatment. Muscle fibre density increased in the diabetic control group, resulting in a capillary/fibre ratio not significantly different from controls. However, with lisinopril, capillary/fibre ratio was approximately $30 \%$ elevated compared to the two other groups.

\section{Discussion}

These previously unreported data demonstrate that $\mathrm{ACE}$ inhibition largely prevented the development of nerve and skeletal muscle dysfunction in diabetic rats. The changes in untreated diabetes are unlikely to result from a cytotoxic action of streptozotocin as they are preventable by insulin treatment $[2,15,29]$. Beneficial effects of lisinopril probably depend on lowering peripheral resistance and improving tissue blood flow, by preventing formation of the vasoconstrictor angiotensin II and perhaps reducing the degradation of vasodilator bradykinin [22]. The argument that vascular actions are important for the functional effects is supported by the correlation of motor nerve conduction velocity with the expected results of chronic blood flow elevation [21], an increase in sciatic nerve capillarisation. In contrast to the diabetic state, chronic vasodilator treatment has no effect on normal nerve conduction $[30,31]$.
Lisinopril treatment had no effect on nerve polyols and worsened the myo-inositol deficit, which suggests that a putative mechanism of dysfunction, linking myo-inositol to Na-K ATPase changes [2], is of little relevance to the present study. It is of interest that omega- 6 essential fatty acid treatment improved nerve conduction velocity without correcting myo-inositol levels, and also increased capillarisation $[23,32]$.

For skeletal muscle, the main changes with diabetes are well-established. Slow twitch soleus, like cardiac muscle, shows prolongations of contraction and relaxation which are likely to depend on abnormal calcium handling [ 15,33 , 34] and impaired sarcoplasmic reticulum function. There is also a reduction in oxidative potential [14] which may be associated with mitochondrial damage $[33,35]$. For fast twitch muscle the main effect of diabetes is on tetanic tension production $[14,15,29]$. Soleus contraction and particularly relaxation deficits were largely prevented by treatment as was the reduction in EDL tetanic tension. This suggests that reduced blood flow may contribute to the deficits. Resting skeletal muscle vascular resistance is increased [19]. Blood flow to the diabetic heart is reduced, in partbecause of decreased endothelial prostacyclin production $[17,18,36]$. Perfusion limitation could be particularly important for skeletal muscles during active periods [37] and they may, therefore, be subjected to hypoxic episodes further exacerbated by re-perfusion damage. Parallels exist between changes occurring as a result of diabetes and of chronic hypoxia. For slow skeletal muscle and heart, both involve prolongations of contraction, and sarcoplasmic reticulum and mitochondrial disruption [38-40]. Thus, in both diabetes and chronic hypoxia, there are shifts towards more energy-efficient myosin isoforms, and calcium homeostasis and oxidative metabolism are compromised.

Increases in muscle capillarisation agree with previous reports of chronic vasodilator action in normal animals [21]. For the highly capillarised soleus, the increase in capillary/fibre ratio was about $10 \%$, and was three times greater for EDL. This may reflect a difference between vascular beds. Soleus is a strong autoregulator, thus, local factors would minimise vasodilator-induced flow changes. EDL has poor autoregulation [41]; therefore, flow changes would be correspondingly greater and the angiogenic stimulus larger [21]. Treatment with the $\alpha_{1}$-adrenoreceptor antagonist prazosin had a greater effect on ca-

Table 6. Capillarisation of sciatic nerve and soleus and extensor digitorum longus muscles

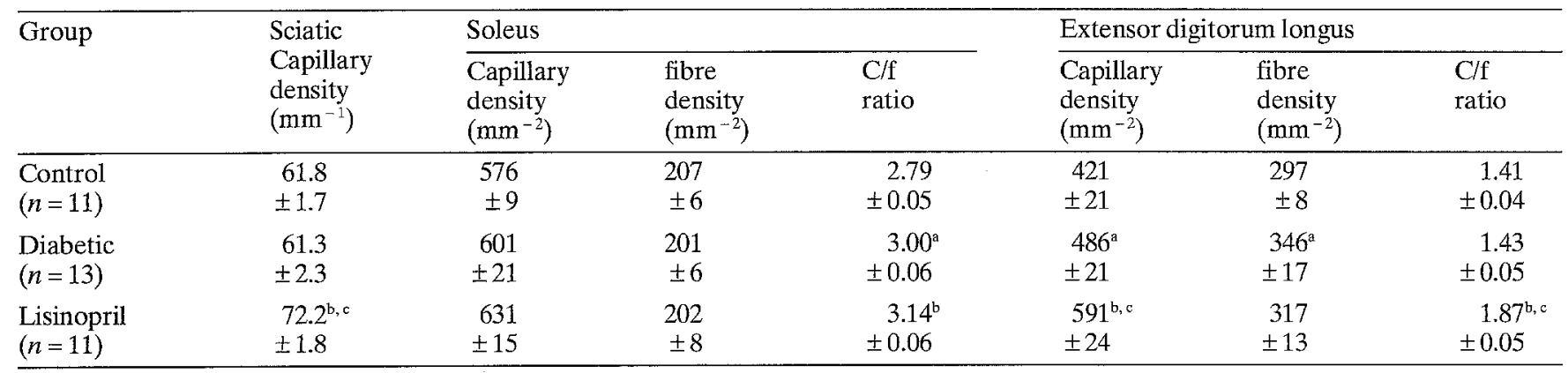

$\mathrm{C} / \mathrm{f}$, capillary/muscle fibre ratio.

Values are mean \pm SEM.

${ }^{\mathrm{a}} p<0.05,{ }^{\mathrm{b}} p<0.01$ difference vs control group; ${ }^{\mathrm{c}} p<0.01$, lisinopril vs diabetic group 


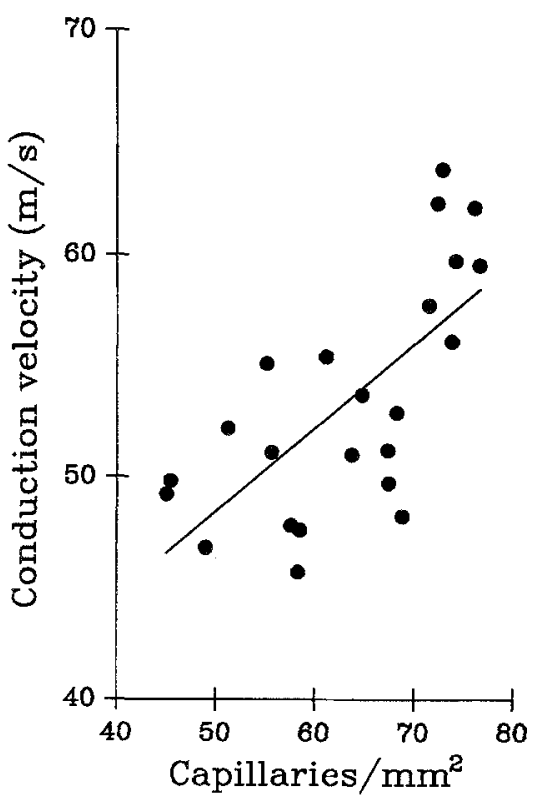

Fig.3. Linear regression of average motor nerve conduction velocity against sciatic nerve endoneurial capillary density for untreated and lisinopril-treated diabetic animals $(r=0.65, p=0.0002)$

pillarisation in fast than slow muscles in non-diabetic animals [21]. The situation in diabetes is, however, more complex particularly for a mixed muscle such as EDL. It is composed of $49 \%$ type IIB fibres which are relatively sparsely capillarised, and $49 \%$ IIA and $2 \%$ type I (slow) fibres that have a well-developed blood supply. With diabetes there is fibre-type-dependent atrophy which is greatest for IIB and least for type I, and there is also fibre damage and splitting [13]. The former would tend to produce an apparent increase in capillary density, whereas the latter would tend to reduce capillary/fibre ratio. In the untreated diabetic group capillary density was increased but capillary/fibre ratio remained unchanged because of an increase in fibre density. In the treated diabetic group, there was a much larger increase in capillary density, the difference from diabetic controls suggesting angiogenesis. In addition, there was an indication that fibre density was less affected than with diabetes alone, suggesting some preservation of muscle integrity. This was checked by comparing EDL fibre areas for diabetic control and lisinopril-treated groups using previously described methods [13]. Mean area for IIB fibres was $16 \%$ increased from $1617.3 \pm 67.4$ to $1871.9 \pm 78.8 \mu^{2}(p<0.05)$ with lisinopril, whereas IIA $\left(1242.2 \pm 36.7\right.$ vs $\left.1300.2 \pm 41.9 \mu \mathrm{m}^{2}\right)$ and type I fibres $\left(972.2 \pm 31.4\right.$ vs $\left.904.7 \pm 39.5 \mu \mathrm{m}^{2}\right)$ were not significantly affected. Given that IIB fibres make up approximately half the muscle, their larger size with lisinopril is sufficient to substantially account for the $9 \%$ decrease in fibre density compared to the untreated diabetic group. Thus, a combination of angiogenesis and fibre preservation explains the large increase in EDL capillary/fibre ratio with lisinopril.

It is of interest that the nerve and muscle deficits prevented by ACE inhibitor treatment were similarly ameliorated by aldose reductase inhibition $[15,37]$, although the latter does not affect capillary density (Came- ron, Cotter and Robertson, unpublished observations). This implies that increased capillarisation is unnecessary for functional improvements, but does not rule out a direct aldose reductase inhibitor effect on the vasculature. For example, increased vascular smooth muscle contractility in diabetes $[42,43]$ may be polyol-pathway-related in an analogous way to striated muscle $[14,15]$.

Another possibility is that both treatments increase cellular ATP availability, albeit achieved via different actions. Thus, excessive polyol pathway activity causes changes in the NADP:NADPH ratio, promoting greater flux through the pentose phosphate pathway, at the expense of glycolytic ATP production [44]. This would be exacerbated by relative ischaemia $[1,11,19]$. Thus, correction of deficits in energy metabolism at the cellular level by aldose reductase inhibition, and at the level of the microenvironment by lisinopril might both restore ATP production sufficiently to allow relatively normal nerve and muscle function. If this is true then the two therapeutic approaches may be complimentary.

In conclusion, ACE inhibition by lisinopril protected nerve and skeletal muscle from the deleterious effects of diabetes. Given that the use of ACE inhibitors in the treatment of hypertension is common in diabetic patients, it is important to note that there may also be some benefits in the treatment of neuropathy and myopathy.

Acknowledgement. This work was supported by a grant from the British Diabetic Association.

\section{References}

1. Low PA, Tuck RR, Takeuchi M (1987) Nerve microenvironment in diabetic neuropathy. In: Dyck PJ, Thomas PK, Asbury AK, Winegrad AI, Porte D (eds) Diabetic neuropathy. Saunders, Philadelphia, pp 266-278

2. Lattimer SA, Sima AAF, Greene DA (1989) In vitro correction of impaired $\mathrm{Na}^{+}-\mathrm{K}^{+}$-ATPase in diabetic nerve by protein kinase C agonists. Am J Physiol 256: E264-E269

3. Mayer JH, Tomlinson DR (1983) Prevention of defects in axonal transport and nerve conduction by oral administration of myoinositol or an aldose reductase inhibitor in streptozotocindiabetic rats. Diabetologia 25: 433-438

4. Cameron NE, Leonard MB, Ross IS, Whiting PH (1986) The effects of sorbinil on peripheral nerve conduction velocity, polyol concentrations and morphology in the streptozotocin-diabetic rat. Diabetologia 29: 168-174

5. Cameron NE, Cotter MA, Robertson S (1989) The effect of aldose reductase inhibition on the pattern of nerve conduction deficits in diabetic rats. Q J Exp Physiol 74: 917-926

6. Yasuda H, Sonobe M, Yamashita M et al. (1989) Effect of prostaglandin $E_{1}$ analogue TFC 612 on diabetic neuropathy in streptozocin-induced diabetic rats, comparison with aldose reductase inhibitor ONO 2235. Diabetes 38: 832-838

7. Sima AAF, Bril V, Nathaniel V et al. (1988) Regeneration and repair of myelinated fibers in sural-nerve biopsy specimens from patients with diabetic neuropathy treated with sorbinil. N Engl J Med 319: 548-555

8. Ward KK, Low PA, Schmelzer JD, Zochodne DW (1989) Prostacyclin and noradrenaline in peripheral nerve of chronic experimental diabetes in rats. Brain 112: 197-208

9. Newrick PG, Wilson AJ, Jakubowski J, Boulton AJM, Ward JD (1986) Sural nerve oxygen tension in diabetes. Br Med J 293: 1053-1054

10. Cameron NE, Cotter MA, Robertson S (1989) Chronic low frequency electrical activation for one week corrects nerve conduc- 
tion deficits in rats with diabetes of three months duration. Diabetologia 32: 759-761

11. Cameron NE, Cotter MA, Low PA (1991) Nerve blood flow in early experimental diabetes in rats: relation to conduction deficits. Am J Physiol 261: E1-E8

12. Tilton RG, Chang K, Pugliese G et al. (1989) Prevention of hemodynamic and vascular albumin filtration changes in diabetic rats by aldose reductase inhibitors. Diabetes 38: 12581270

13. Cotter MA, Cameron NE, Lean D, Robertson S (1989) Effects of long-term streptozotocin diabetes on the contractile and histochemical properties of rat muscles. Q J Exp Physiol 74: 65-74

14. Cameron NE, Cotter MA, Robertson S (1989) Contractile properties of cardiac papillary muscle in streptozotocin-diabetic rats and the effects of aldose reductase inhibition. Diabetologia $32: 365-370$

15. Cameron NE, Cotter MA, Robertson S (1990) Changes in skeletal muscle contractile properties in streptozocin-induced diabetic rats and role of polyol pathway and hypoinsulinemia. Diabetes 39: 460-465

16. Robertson S (1989) Changes in skeletal muscle contractile properties in rats fed a dietary galactose supplement. J Physiol (Lond) 409: 76P (Abstract)

17. Rosen R, Beck E, Rosen P (1988) Early vascular alterations in the diabetic rat heart. Acta Physiol Hung 72:3-11

18. Rosen P, Rosen R, Hohl C, Reinauer H, Klaus W (1984) Reduced transcoronary exchange and prostaglandin synthesis in diabetic rat heart. Am J Physiol 247: H563-H567

19. Monfano WM, Eliasson SG, Shimazaki S, Sugimoto H (1988) Regional blood flow in resting and stimulated sciatic nerve of diabetic rats. Exp Neurol 99: 607-614

20. Yagi S, Takata S, Kiyokawa H, et al. (1988) Effects of insulin on vasoconstrictive responses to norepinephrine and angiotensin II in rabbit femoral artery and vein. Diabetes 37: 1064-1067

21. Hudlicka O, Tyler KR (1986) Angiogenesis: the growth of the vascular system. Academic Press, New York

22. Sweet CS, Ulm EH (1988) Lisinopril. Cardiovasc drug reviews 6: 181-191

23. Cameron NE, Cotter MA, Robertson S (1991) Effects of essential fatty acid dietary supplementation on peripheral nerve and skeletal muscle function and capillarization in streptozocin diabetic rats. Diabetes 40: 532-539

24. Ziada AMAR, Hudlicka O, Tyler KR, Wright AJA (1984) The effect of long term vasodilation on capillary growth and performance in rabbit heart and skeletal muscle. Cardiovasc Res 18: $724-732$

25. Stribling D, Mirrless DJ, Harrison HE, Earl DCN (1985) Properties of ICI 128436, a novel aldose reductase inhibitor and its effects on diabetic complications in the rat. Metabolism 34: 336-344

26. Duncan DB (1955) Multiple range and multiple F tests. Biometrics 11: 1-42

27. Kramer CY (1956) Extension of multiple range tests to group means with unequal numbers of replications. Biometrics 12:307310

28. Seneviratne KN, Peiris OA (1969) The effects of hypoxia on the excitability of the isolated peripheral nerves of alloxan-diabetic rats. J Neurol Neurosurg Psychiat 32: 462-469

29. Paulus SF, Grossie J (1983) Skeletal muscle in alloxan diabetes. A comparison of isometric contractions in fast and slow muscle. Diabetes 32: 1035-1039

30. Zochodne DW, Ward K, Low PA (1988) Guanethidine adrenergic neuropathy: an animal model of selective autonomic neuropathy. Brain Res 461: 10-16
31. Zochodne DW, Huang Z, Ward K, Low PA (1990) Guanethidine adrenergic sympathectomy augments endoneurial perfusion and lowers endoneurial microvascular resistance. Brain Res 519: $112-117$

32. Tomlinson DR, Robinson JP, Compton AM, Keen P (1989) Essential fatty acid treatment - effects on nerve conduction, polyol pathway and axonal transport in streptozotocin diabetic rats. Diabetologia 32: 655-659

33. Afzal N, Ganguly PK, Dhalla KS, Pierce GN, Singal PK, Dhalla NS (1988) Beneficial effects of verapamil in diabetic cardiomyopathy. Diabetes 37: 936-942

34. Eibschutz B, Lopaschuk GD, McNeill JH, Katz S (1984) $\mathrm{Ca}^{2+}$ transport in skeletal muscle sarcoplasmic reticulum of the chronically diabetic rat. Res Commun Chem Pathol Pharmacol 45: 301-304

35. Chao TT, Ianuzzo CD, Armstrong RB, Albright JT, Anapolle SE (1976) Ultrastructural alterations in skeletal muscle fibres of streptozotocin-diabetic rats. Cell Tiss Res 168: 239-246

36. Rot DM, Reibel DK, Lefer AM (1983) Vascular responsiveness and eicosanoid production in diabetic rats. Diabetologia 24:372376

37. Cameron NE, Cotter MA, Robertson S (1987) Effects of experimental diabetes on contractile properties of skeletal muscles of the rat and the effect of treatment with the aldose reductase inhibitor Statil (ICI 128436). J Physiol (Lond) 387: 43 P (Abstract)

38. Bowers WD, Burlington RF, Whitten BK, Daum RC, Posiviata MA (1971) Ultrastructural and metabolic alterations in myocardium from altitude-acclimated rats. Am J Physiol 220: 1885-1889

39. Maher JT, Goodman AL, Bowers WD, Hartley LH, Angelakos ET (1972) Myocardial function and ultrastructure in chronically hypoxic rats. Am J Physiol 223: 1029-1033

40. Mcgrath JJ, Bullard RW, Komives GK (1969) Functional adaptation in cardiac and skeletal muscle after exposure to simulated high altitude. Fed Proc 28: 1307-1311

41. Folkow B, Halicka HD (1968) A comparison between "red" and "white" muscle with respect to blood supply, capillary surface area and oxygen uptake during rest and exercise. Microvasc Res $1: 1-14$

42. Scarborough NL, Carrier GO (1983) Increased alpha $a_{2}$-adrenoreceptor mediated vascular contraction in diabetic rats. $J$ Autonom Pharmacol 3: 177-183

43. Morff RJ (1990) Microvascular reactivity to norepinephrine at different arteriolar levels and durations of streptozocin-induced diabetes. Diabetes 39: 354-360

44. Davidson WS, Murphy DG (1985) Aldehyde reductases and their involvement in muscular dystrophy. In: Flynn G (ed) Enzymology of carbonyl metabolism 2: aldehyde dehydrogenase, aldo-keto reductase and alcohol dehydrogenase. A R Liss Inc., New York, pp 251-263

Received: 18 June 1991

and in revised form: 2 September 1991

Dr. N.E. Cameron

School of Biomedical Sciences

Division of Physiology

University of Aberdeen

Marischal College

Aberdeen AB $91 \mathrm{AS}$

Scotland

UK 